\title{
Article \\ Use of Foamed Cement Banking for Reducing Expressways Embankment Settlement
}

\author{
Yuedong $\mathrm{Wu}^{1,2}$, Hui Liu ${ }^{1,2} \mathbb{D}$ and Jian Liu ${ }^{1,2, *}$ \\ 1 College of Civil and Transportation Engineering, Hohai University, Nanjing 210098, China; \\ hhuwyd@163.com (Y.W.); lxiao_hui@hhu.edu.cn (H.L.) \\ 2 Key Laboratory of Ministry of Education for Geomechanics and Embankment Engineering, Hohai University, \\ Nanjing 210098, China \\ * Correspondence: 20170053@hhu.edu.cn; Tel.: +86-183-6296-0323
}

\footnotetext{
check for updates

Citation: Wu, Y.; Liu, H.; Liu, J. Use of Foamed Cement Banking for Reducing Expressways Embankment Settlement. Appl. Sci. 2021, 11, 11959. https: / /doi.org/10.3390/ app112411959
}

Academic Editors: Daniel Dias and Bing Bai

Received: 14 October 2021

Accepted: 13 December 2021

Published: 15 December 2021

Publisher's Note: MDPI stays neutral with regard to jurisdictional claims in published maps and institutional affiliations.

Copyright: (c) 2021 by the authors. Licensee MDPI, Basel, Switzerland. This article is an open access article distributed under the terms and conditions of the Creative Commons Attribution (CC BY) license (https:// creativecommons.org/licenses/by/ $4.0 /)$.

\begin{abstract}
Expressways are often built on soft ground, the foundation of which is not processed adequately during the construction period. Consequently, the traffic safety and embankment stability will be seriously affected due to uneven settlement. The technology of holing the embankment and replacing foamed cement banking (FCB) could control the settlement of an embankment without road closure, thus reduce the impact of construction on normal operation of highways. In this paper, the principle of FCB is described. Additionally, a sedimentation ratio calculation method, through the analysis of the settlement load ratio, is proposed for calculating the roadbed replacement thickness. This paper takes the example of the test section EK0 + 323 on Shen-Jia-Hu expressway in Zhejiang Province and combines with site settlement monitoring data to confirm the effectiveness of the calculation method proposed.
\end{abstract}

Keywords: construction disturbance; replacement of embankment; foamed cement banking technology; post-construction settlement; method of replacement thickness calculation

\section{Introduction}

With the rapid development of expressway construction, in China, construction on soft ground is sharply increasing, such as Shen-Jia-Hu Expressway that passes through soft soil [1,2]. Owing to shortened construction periods and to the rheological properties of soft soil, among other reasons, the embankment after settlement of many highways opened abroad is too high, which does not meet relevant regulatory requirements (i.e., post-construction should be less than $30.0 \mathrm{~cm}$ ) [3]. The post-construction settlement of expressways has become a major type of expressway damage, which will not only seriously affect the vehicle's road speed, traffic safety, and driving comfort, but also seriously affect the stability and safety of the highway itself [4-6].

In order to reduce post-construction settlement, the embankment is replaced with light soil to reduce the overburden load and control the settlement [7,8]. At present, the widely used light soils mainly include EPS beads-mixed lightweight soil, EPS block, and foamed cement banking, which include good integrity, light mass, and convenient construction. The lightweight soil's cohesion, global strength, bulk density, and other parameters can be adjusted by adjusting the output of cement and foam [9]. The advantages and disadvantages of various methods are shown in Table 1. Foamed cement banking research is already well underway in numerous countries [10-12], and some results have been achieved in practice. Compared with other materials, the FCB has a shorter construction period, lower curing time, and higher construction quality, thus it has broad application prospects [13,14]. As FCB's bulk density is only conventional soil bulk density of $1 / 4$ to $1 / 8$, its use as a replacement of embankment material [15-17], can not only reduce the base load pressure, but can also reduce the total settlement and differential settlement [18]. Replacing the undisturbed soil with lightweight soil to process the post-construction settlement of 
expressway under traffic control seriously affected highway traffic operations. Especially, there are no closed roads (ramps) during construction, the lightweight soil is being put down to achieve subgrade compactness, that causes huge economic losses due to the road closure.

Table 1. Comparison of different lightweight fills.

\begin{tabular}{|c|c|c|}
\hline Material Type & Advantage & Disadvantage \\
\hline $\begin{array}{l}\text { EPS beads-mixed } \\
\text { lightweight soil }\end{array}$ & $\begin{array}{l}\text { Low density and compressibility; } \\
\text { high strength; environmental } \\
\text { protection. }\end{array}$ & $\begin{array}{l}\text { Difficult construction; high } \\
\text { material cost; poor corrosion } \\
\text { resistance. }\end{array}$ \\
\hline EPS block & $\begin{array}{l}\text { Low density; stable nature; } \\
\text { convenient construction. }\end{array}$ & $\begin{array}{l}\text { High material cost; poor } \\
\text { impact resistance; easy to } \\
\text { local cavity. }\end{array}$ \\
\hline $\begin{array}{l}\text { Foamed cement } \\
\text { banking }\end{array}$ & $\begin{array}{l}\text { Low density; good integration; high } \\
\text { strength and corrosion resistance; } \\
\text { short construction period. }\end{array}$ & $\begin{array}{l}\text { High cement hydration heat; } \\
\text { high material cost. }\end{array}$ \\
\hline
\end{tabular}

In this paper, foamed cement replacement is carried out on both sides of the embankment, which does not affect the normal traffic operation during replacement construction, its use is targeted and flexible, and only small settlement occurs after improvement. Combined with Shen-Jia-Hu EK0 + 323 highway section, this paper verifies the advantages of FCB in dealing with embankment settlement without road closure. Through the analysis of dynamic monitoring data of Shen-Jia-Hu expressway's subgrade settlement, and according to the proportional relationship between settlement and load, the calculation method of embankment replacement thickness is proposed, which can be applied to complex construction processes, this work can thus provide a reference for similar future projects.

\section{Design Principles and Calculation Method}

\subsection{Principle of FCB}

FCB is a new technology for reducing embankment settlement while ensuring the normal operation of road transport, its schematic diagram is shown in Figure 1. First, the amount of FCB replacement needed is based on the amount of static load of embankment to be uninstalled, which is, in turn, used to design the transverse hole construction plan. Then, drilling horizontal holes on the embankment continuously, with the hole machinery along the embankment on one side or both sides, next, FCB is injected directly into the holes using perfusion enrichment after the hole formed. The unit weight of regular FCB filling is $5.5-6.0 \mathrm{kN} / \mathrm{m}^{3}$, which is $1 / 3$ to $1 / 4$ of the general soil bulk density (i.e., $20 \mathrm{kN} / \mathrm{m}^{3}$ ), to effectively reduce the embankment permanent load. The undisturbed foundation soil becomes super-solid, and the effect of the improvement is clear. The normal operation of the highway will not be affected during construction.

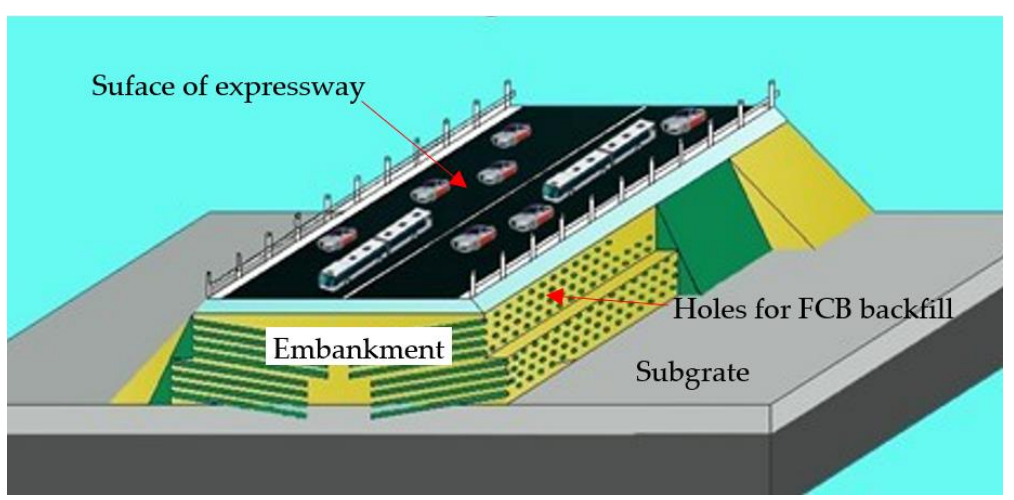

Figure 1. Embankment FCB replacement construction by citing transverse holes. 


\subsection{Calculation Method}

The most important link of FCB displacement control of a subgrade is to identify the replacement thickness of the roadbed. This currently relies heavily on the layerwise summation method for estimation of total deposition, as well as comparative analysis with settlement monitoring data available before improvement, leading to the determination of the replacement thickness [18] in the transverse hole for the filling of the road embankment stage, which mainly depends on the layerwise summation method. When this method is used to calculate the settlement under complex loading and unloading conditions, it produces large errors.

For easier calculation of displacement thickness. Chen [19] had proposed a calculation formula of unloading quantity, but it is necessary to be combined with engineering practice to determine the parameters, which has a high cost. Thus, based on the formula proposed by Chen and the ratio variation between load and settlement, a method for calculating unloading according to the settlement is proposed as follows:

$$
P_{\mathrm{c}}=h \cdot\left(\gamma_{1}-\gamma_{0}\right)
$$

where $\gamma_{1}$ is the embankment unit weight that generally ranges between 19.0 and $21.0 \mathrm{kN} / \mathrm{m}^{3}$, and $\gamma_{0}$ is the foamed lightweight concrete embankment wet unit weight ranging between 5.5 and $6.0 \mathrm{kN} / \mathrm{m}^{3} ; P_{c}$ is the embankment unloading amount, and $h$ is the replacement thickness.

At present, the existing settlement data is mainly used to predict the settlement curve, and the replacement thickness is determined according to the result. The weight of embankment was reduced by replacing the undisturbed soil, which can reduce settlement. Therefore, when the monitored settlement data does not meet the requirements, the embankment should be improved. The unloading value is mainly determined by the difference between the bulk density of the replacement material and the undisturbed soil mass. Thus, the method proposed in this paper has an advantage of calculating the unloading value of the overload embankment to a certain extent, even though there is a difference in establishing the initial expression. To devise an expression that can calculate the replacement thickness under different conditions, including overload, equivalent load, and under load conditions (i.e., after embankment soil replacement with FCB), further research on the relationship between foundation consolidation settlement and pressure must be conducted.

Based on the assumption that unloading construction is not performed on the embankment, the embankment ultimate settlement under pressure $P_{0}$ is $S_{\infty}^{p+\Delta p}$, and the observed foundation settlement before unloading construction is $S_{m}$. If embankment unloading construction is implemented and the unloading amount is $P_{c}$, the embankment residual weight $P_{u}^{1}$ induces the ultimate settlement $S_{\infty}^{h}$, and a formula for settlement calculation can be given as follows:

$$
\frac{S_{\infty}^{p+\Delta p}}{S_{\infty}^{h}}=\frac{P_{0}}{P_{u}^{1}}
$$

Owing to the fact that the settlement calculation considers rebound under unloading conditions, the following concepts should be clarified. When unloading $P_{c}$ in FCB embankment replacement is completed, the load $P_{c} \cdot S_{m} / S_{\infty}^{P+\Delta P}$ had converted into effective load, unloading this part of the load will cause rebound. As a result, this part of the capacity should take the swelling index caused by unloading into account, the swelling index is usually taken as $\delta$ times the compression settlement (engineering empirical suggested range of values: $0.05-0.03)$. Meanwhile, the other part of the load that is not converted is $P_{c} \cdot\left(1-S_{m} / S_{\infty}^{P+\Delta P}\right)$, and its settlement computation is suggested to confirm normal compression settlement. Therefore, the settlement caused by unloading is expressed as:

$$
S_{c}=\frac{\left[1-(1-\delta) \frac{S_{m}}{S_{\infty}^{P+\Delta P}}\right]}{P_{0}} \cdot P_{c} \cdot S_{\infty}^{P+\Delta P}
$$


After unloading construction, the actual remaining consolidation settlement $S_{m}^{1}$ is expressed as:

$$
S_{m}^{1}=S_{m}-S_{c}=S_{m}-\frac{\left[1-(1-\delta) \frac{S_{m}}{S_{\infty}^{P+\Delta P}}\right]}{P_{0}} \cdot P_{c} \cdot S_{\infty}^{P+\Delta P}
$$

Considering the allowable post-construction settlement $\Delta S$ in design work, by summing the actual remaining settlement $S_{m}^{1}$ and allowable post-construction settlement $\Delta S$, the total ultimate settlement $S_{\infty}^{h}$ induced by the residual embankment load after moving the load $P_{c}$ is obtained:

$$
\begin{gathered}
S_{m}^{1}+\Delta S=S_{\infty}^{h} \\
P_{c}=\frac{P_{0} \cdot\left(S_{\infty}^{P+\Delta P}-S_{m}-\Delta S\right)}{(1-\delta) \cdot S_{m}}=\vartheta \cdot P_{0} \cdot\left(\frac{S_{r}-\Delta S}{S_{m}}\right)
\end{gathered}
$$

where $S_{r}$ is the residual settlement before improvement with FCB, $S_{r}=S_{\infty}^{P+\Delta P}-S_{m} ; S_{m}$ is the monitoring data during construction; $S_{\infty}^{P+\Delta P}$ is the computed ultimate settlement under the embankment load $P_{0}$ function; $P_{0}$ is the embankment gravity load, and $\Delta S$ is the design-allowable post-construction settlement for which a local standard is suggested for determining its value. $\vartheta$ is the rebound correction factor expressed as $\vartheta=1 /(1-\delta)$, where $\delta$ is the swelling index within the range $0.05-0.3$.

Under the condition that the embankment design applies overload pre-loading, if the calculated subgrade unloading confirms that $P_{c} \leq P_{0}-P_{u}, P_{u}$ is the amount of overload, the post-construction settlement requirement can be satisfied after removing the overload pressure. When $P_{c}>P_{0}-P_{u}$, except for removing overload, it is necessary to apply FCB to process the excess load, $P_{\mathcal{c}}-\left(P_{0}-P_{u}\right)$. If equivalent load pre-compression is applied in embankment reinforcement, the computation of FCB replacement thickness should take the unloading value $P_{c}$ into account. If the embankment design condition is under load pre-compression $\left(P_{0} \leq P_{u}\right)$, computation of the FCB replacement thickness should confirm the expression: $P_{c}+P_{u}-P_{0}$.

In order to use equation (6) to calculate unloading value, parameters $P_{0}$ and $S_{m}$ can be acquired by measuring before unloading, and $\delta$ is determined either by laboratory sample testing or by practical engineering empirical estimation. $\Delta S$ is allowable postconstruction settlement decided by local standard regulations [20]. The ultimate settlement $S_{\infty}^{P+\Delta P}$ contributing to the pre-loading effect before unloading, it can be obtained by conventional layerwise summation method or by prediction of measured settlement during preloading construction.

\section{Field Study on Shen-Jia-Hu Highway}

\subsection{Engineering Situation}

The practical site for experiments was part of the Zhejiang Shenjiahua Hangzhou Expressway (Lianhang Section) project (hereafter referred to as the Shen-Jia-Hu expressway), which is located on Hang-jia-hu plain, the geographical location of Shen-Jia-Hu is shown in Figure 2. This region has a developed economy, high population density, and high transportation requirements. However, the numerous lakes and rivers cause a large amount of soft soil in this region. Most of its road sections pass through soft soil foundation, which contain soils characterized by high moisture content, high compression, low strength, and low permeability, which will cause greater road settlement.

In view of the engineering geological conditions, in addition to conventional improvement methods such as grout spray pile (pile diameter $500.0 \mathrm{~mm}, 3.05$ million linear meters) and prestressed concrete pipe pile (pile diameter $400.0 \mathrm{~mm}$, wall thickness $60.0 \mathrm{~mm}, 590$ thousand linear meters), Shen-Jia-Hu expressway also adopted equal preloading (2.39 million $\mathrm{m}^{3}$ ) along the whole line. The expressway subgrade was filled with earthworks mixture. The foundation improvement mainly adopted stacking load precompaction and combined the plastic wick drain. The road section chosen for experiments is the EK $0+323$ ramp bridge road, which has a $10 \mathrm{~m}$ wide pavement, a $3.25 \mathrm{~m}$ high embank- 
ment, and a 1:1.5 slope grade. The soil cohesion and internal friction angle were obtained through direct shear experiment, and the soil water content was obtained through the oven-drying method. The other parameters and specific steps were determined according to the Standard for geotechnical testing method [3], and the parameters are given in Table 2. It should be noted that the soil parameters were obtained after the surcharge preloading method. The cohesion values were relatively higher than other soil.

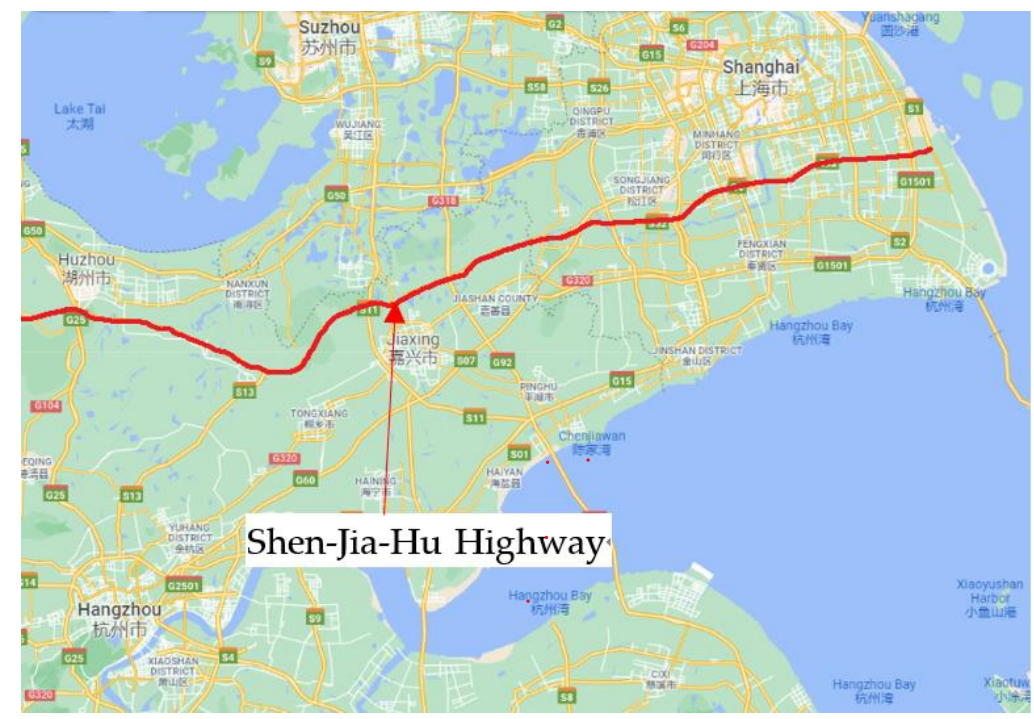

Figure 2. Geographic position of Shen-Jia-Hu expressway.

Table 2. Soil parameters.

\begin{tabular}{|c|c|c|c|c|c|c|c|c|}
\hline Type of Soil Layer & $\begin{array}{c}\text { Thickness } \\
\text { (m) }\end{array}$ & $\begin{array}{c}\text { Water } \\
\text { Content } \\
(\%)\end{array}$ & $\begin{array}{l}\text { Natural } \\
\text { Density } \\
\left(\mathrm{g} / \mathrm{cm}^{3}\right)\end{array}$ & Void Ratio & $\begin{array}{l}\text { Compression } \\
\text { Modulus } \\
\text { (MPa) }\end{array}$ & $\begin{array}{c}\text { Compression } \\
\text { Factor } \\
\left(\mathrm{Mpa}^{-1}\right)\end{array}$ & $\begin{array}{c}\text { Cohesion } \\
\text { (kPa) }\end{array}$ & $\begin{array}{c}\text { Internal } \\
\text { Friction } \\
\text { Angle }\end{array}$ \\
\hline Planting soil & 2.1 & - & - & - & - & - & - & - \\
\hline Silty clay & 1.2 & 22.7 & 1.95 & 0.64 & 7.24 & 0.22 & 45.00 & 15.20 \\
\hline Silt clay & 10.4 & 51.5 & 1.70 & 1.40 & 2.91 & 0.83 & 32.50 & 20.30 \\
\hline Clay & 11.2 & 30.7 & 1.90 & 0.86 & 5.89 & 0.32 & 30.30 & 23.90 \\
\hline Fine sand interlayer & 0.4 & 24.5 & 1.98 & 0.70 & 16.81 & 0.10 & - & - \\
\hline Silty clay & 3.9 & 23.4 & 1.99 & 0.68 & 10.93 & 0.15 & 40.00 & 26.50 \\
\hline
\end{tabular}

\subsection{Construction Process}

According to the FCB construction process, the embankment slope was excavated to prepare a construction plane, and then drilling equipment was used to drill lateral holes to a designed depth in the embankment, which would not affect highway traffic operations. PVC plastic tubing or plug gauge was inserted in the hole to test the hole quality, and then the FCB material was cast in the holes, the holes were drilled in the embankment slop by the drilling machine as shown in Figure 3. A construction point worthy of attention is that the FCB pouring process should be implemented immediately after drilling the holes avoid a hole deforming under the overlying embankment load. The slope cover was cast using FCB material after all the holes were filled with FCB. The key point in this construction step is to cast the slope according to design's required proportional grading. Finally, the embankment slope was covered with soil and landscaped with plants.

\subsection{Improvement before Analysis of Monitoring Data}

Settlement observation was conducted during the period January 2010 to August 2010. In the EK $0+323$ section, the largest settlement, reaching over $129.0 \mathrm{~mm}$, occurred on a road bridge, affecting the speed of traffic and highway safety. In September 2010, asphalt concrete pavement filling was applied, and it was later observed that the roadbed continued 
sinking at a larger sedimentation rate (i.e., $9.1 \mathrm{~mm} / \mathrm{month}$ ). On 25 March 2011, the settlement reached its maximum, $219.0 \mathrm{~mm}$. Measurements of the settlement before the application of FCB are shown in Figure 4.

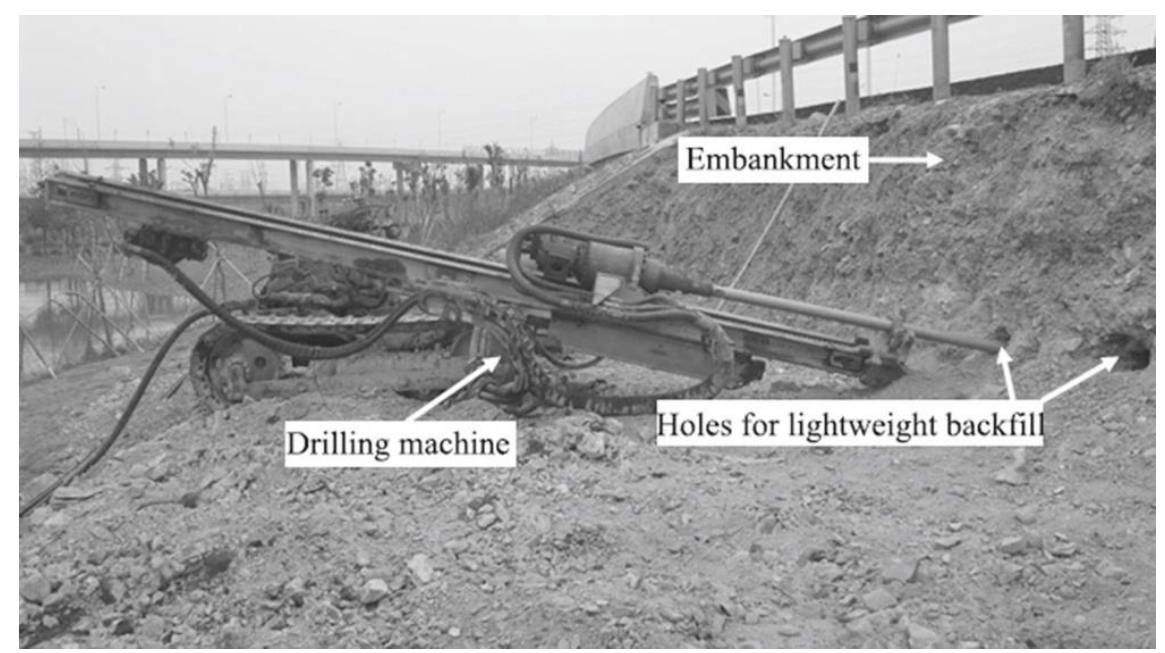

Figure 3. Drilling holes on north sides of the embankment. Reprinted with permission from Ref. [18]. Copyright 2021 IEEE Proceedings.

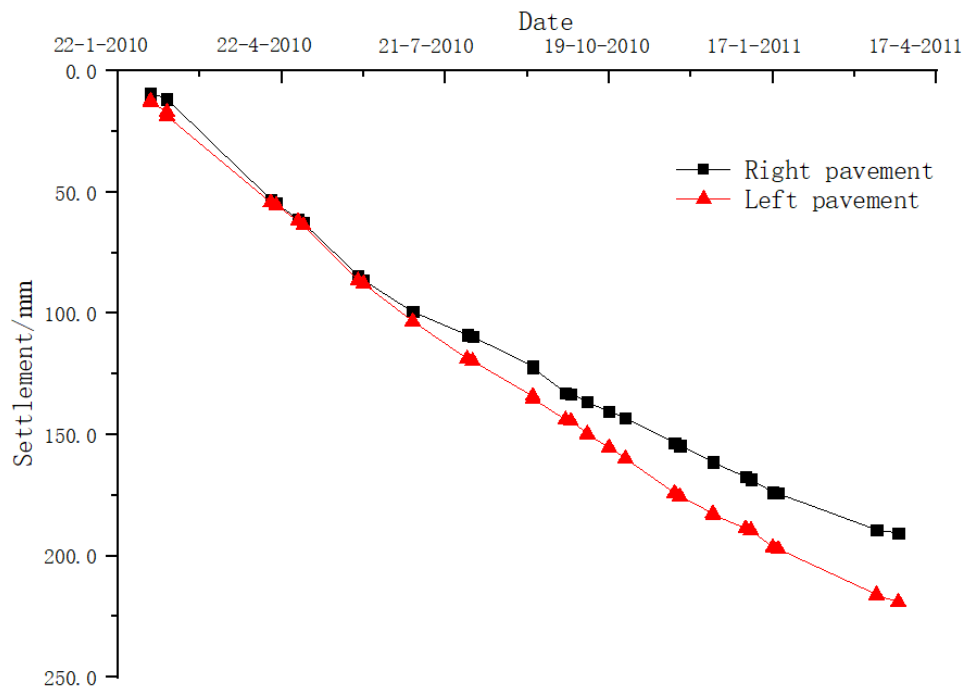

Figure 4. Total embankment settlement before improvement with FCB.

As shown in Figure 4, until 25 March 2011, no obvious convergence trend in the subsidence curves was noted, based on the post-construction monitoring settlement data. The reason may be due to tight deadlines resulting in inadequate preloading foundation, making the work required after settlement too large in scope. A settlement prediction formula [21] for EK0 + 323 settlement was used to demonstrate this method. Based on the bridge sections of EK0 +323 and two settlement observation sections, the settlement prediction results are shown in Table 3. To simplify the forecasting process and meet the requirements of settlement prediction analysis with prediction process, secondary consolidation settlement was not considered.

The settlement prediction results showed that section EK0 + 323's settlement will be up to $402.2 \mathrm{~mm}$. Not taking into account the largest remaining secondary consolidation, settlement will again lead to vehicle bumping; thus, holes filled with bubbled and mixed FCB were introduced in section EK0 + 323 for improvement.

Following the above-described unloading calculation method, the FCB replacement quantity was $102.4 \mathrm{~m}^{3}$, and the total FCB volume for embankment improvement was 
separated into 774 lateral holes with diameters of $\Phi 150 \mathrm{~mm}$ (including 719 holes that were $6.0 \mathrm{~m}$ deep and 55 holes that were $4.0 \mathrm{~m}$ deep).

Table 3. Settlement forecast.

\begin{tabular}{cccccc}
\hline Section & $\begin{array}{c}\text { Settlement } \\
\text { Rate March } \\
\text { (mm/month) }\end{array}$ & $\begin{array}{c}\text { Present } \\
\text { Settlement } \\
(\mathbf{m m})\end{array}$ & $\begin{array}{c}\text { The Settlement } \\
\text { Forecast } \\
(\mathbf{m m})\end{array}$ & $\begin{array}{c}\text { Residual } \\
\text { Settlement } \\
(\mathbf{m m})\end{array}$ \\
\hline \multirow{2}{*}{ EK0 +323} & left & 9.2 & 189.6 & 292.9 & 103.3 \\
& right & 11.2 & 219.3 & 402.2 & 182.9 \\
\hline
\end{tabular}

\subsection{Effectiveness Analysis of Improvement}

For the FCB improvement of section EK0 + 323, the embankment settlement data based on dynamic monitoring data analysis is shown in Figure 5.

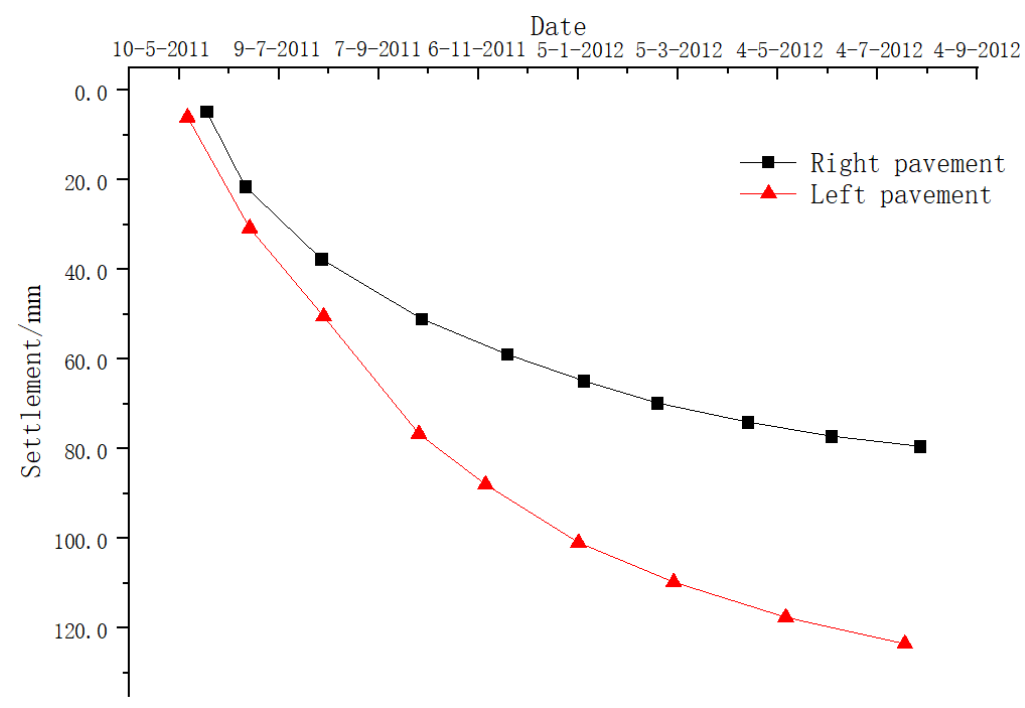

Figure 5. Total embankment settlement after improvement with FCB.

Section EK0 + 323 is located on a bridgehead segment, and according to the preconstruction settlement prediction, the remaining post-construction settlement of the left and right sides were 182.9 and $103.3 \mathrm{~mm}$, respectively, until May 2011. As shown in Figure 5, after improvement with FCB on both the left and right sides, the settlements were 57.1 and $44.2 \mathrm{~mm}$ after embankment improvement finished (i.e., October 2011), respectively. Comparing the two sites, after initial construction of the section, the settlement exhibited a relatively sharp decreasing trend. The reason was that during the improvement process, the construction disturbance caused an impact on the embankment. The settlement after improvement was approximately $70 \%$ of the predicted settlement. Additionally, the average remaining settlement was $43.2 \mathrm{~mm}$, meeting the residual settlement thresholds (i.e., less than the $30.0 \mathrm{~cm}$ ) of the expressway embankment after improvement.

The results of EK0 + 323 after replacement improvement using the proposed technology revealed a monthly settlement rate of $50 \%$, which was a reduction from the remaining settlement after construction of $70 \%$. After improvement with the lateral hole replacement technology, the remaining settlement met the threshold for the settlement control after construction standards, and effectively suppressed the recurrence of bumping.

\section{Discussion}

Using FCB to replace the undisturbed soil of embankment on both sides cannot affect the normal operation of the highway. It can avoid economic losses caused by closure. FCB has very good fluidity, so it can be pumped to the designed depth and has a fast construction speed, so the construction period can be greatly shortened. 
By calculating the replacement thickness of the embankment by using the formula proposed in this paper, after improving the embankment with this thickness, the settlement of embankment begins to stabilize. The residual settlement of embankment meets the thresholds (i.e., less than the $5.0 \mathrm{~cm}$ ). Thus, this calculation formula, proposed in this paper, can be used in embankment improvement projects. During the improvement of the embankment, the settlement has a sharply increasing trend. It may be caused by embankment disturbance during the construction period. Thus, embankments should be replaced by the undisturbed soil in the same section, which is used to analyze the impact of construction disturbance. Additionally, monitoring the road surface settlement without embankment improvement, which is used to prove that the decrease in foundation settlement rate is caused by FCB improvement.

\section{Conclusions}

In this paper, Shen-Jia-Hu Expressway section EK0 + 323 served as the basis for a project to introduce new FCB design principles and calculation methods. From the results obtained through experiments on the test section as well as via subgrade settlement dynamic monitoring data analysis, the following conclusions can be drawn.

(1) The FCB method is an effective means to reduce highway embankment differential settlement without disturbing normal traffic, which has the following advantages: (1) convenience for continued highway operation, (2) high flexibility, and (3) an ideal improvement effect.

(2) Based on the proportional relationship between unloading amount and settlement value, a calculation method for unloading amount determination was developed herein. This method was used to determine the amount of embankment replacement and apply it to actual projects, which was then verified to be practical and accurate.

(3) According to the theoretical settlement value predicted in the previous article, and from the analysis of field monitoring data from practical highway projects, the pavement monthly settlement ratio was theoretically reduced by $50 \%$ and the residual post-construction settlement by $60 \%$ when transverse drilling and FCB improvement were completed. Therefore, in practice, FCB improvement is an effective means to control and reduce embankment differential settlement.

\footnotetext{
Author Contributions: The formal analysis, formula reasoning, and the performance of the experiment, as well as the original draft preparation, were completed by H.L.; Review and editing were completed by Y.W. and J.L. All authors have read and agreed to the published version of the manuscript.
}

Funding: The research was funded by supported by the Fundamental Research Funds for the Central Universities, number B200204036.

Institutional Review Board Statement: Not applicable.

Informed Consent Statement: Not applicable.

Data Availability Statement: Data sharing not applicable. No new data were created or analyzed in this study.

Conflicts of Interest: The authors declare no conflict of interest.

\section{References}

1. Wang, Y.S. Settlement of soft soil foundation of Expressway. China J. Highw. Transp. 1993, 6, 61-66.

2. Zhou, S.; Wang, B.L.; Shan, Y. Review of research on high-speed railway subgrade settlement in soft soil area. Railw. Eng. Sci. 2020, 28, 129-145. [CrossRef]

3. CCCC Second Highway Survey and Design Institute. Specifications for Design of Highway Subgrades; China Communications Press: Beijing, China, 2015; pp. 69-70, 84-85.

4. Li, J.; He, D.P.; Peng, Y.H. Alleviating bump at bridge-head using geocell flexible approach slab. In Proceedings of the Third International Conference on Transportation Engineering, Chengdu, China, 23-25 July 2011; ASCE: Reston, VA, USA, 2011; pp. 1609-1617. 
5. Pan, X.D.; Du, Z.G.; Yang, X.G. Evaluation indexes of the impact of vehicle bumping at bridge-head on driving safety. J. Tongji Univ. Nat. Sci. 2006, 34, 634-637.

6. Zhao, X.X.; Yang, L.J. Analysis and management methods for the road and bridge transition's sedimentation on the soft clay ground in Shanghai. J. Lanzhou Jiaotong Univ. 2008, 27, 37-40.

7. Lu, T.; Yang, P.; Li, M.X.; Yi, L.H. Analysis of deformation behavior of foamed lightweight soil subgrade on soft soil foundation. Subgrade Eng. 2018, 46, 38-41.

8. Liu, H.L.; Yi, F.; Chen, Y.H. Study on method of laterally replacing subgrade of existing expressway by light soil. J. Highw. Transp. Res. Dev. 2019, 36, 19-27.

9. Huang, T.Y.; Wang, X.Q.; Fang, G.W.; Zhang, H.P.; Diao, H.G. Design and calculation methods of light soil replacement after preloading in the soft soil foundation of the highway. Urban Rapid Rail Transit 2019, 37, 59-63.

10. Jones, M.R.; McCarthy, A. Utilizing unprocessed low-lime coal fly ash in foamed concrete. Fuel 2005, 84, 1398-1409. [CrossRef]

11. Wang, Z.J.; Sun, Z.C.; Lu, L.; Li, J.B. Study on the uniaxial compressive mechanical properties of foamed mixture lightweight soil with polypropylene fibers. Chin. J. Undergr. Space Eng. 2018, 16, 1021-1029.

12. Li, Y.Z. Foamed cement banking for reinforcing soft ground. Miner. Explor. 2008, 11, 66-68.

13. Gao, Y.L.; Xiao, M.Q.; Guan, H.X. Foamed cement banking and its utilization in highway engineering. Bull. Chin. Silic. Soc. 2016, $35,2432-2438$.

14. Deng, H.W. Bubble-mixed light soil applied in a metro high-fill roadbed. Urban Rapid Rail Transit 2018, 31, 88-91.

15. Ding, X.H. Study on design and calculation of foamed cement banking. Subgrade Eng. 2017, 35, $146-151$.

16. Jamnongpipatkul, P.; Dechasakulsom, M.; Sukolrat, J. Application of air foam stabilized soil for bridge-embankment transition zone in Thailand. In Proceedings of the American Society of Civil Engineers GeoHunan International Conference, Changsha, China, 3-6 August 2009; ASCE: Reston, VA, USA, 2009; pp. 181-193.

17. Xiao, L.J. Foamed Cement Banking and Applications in Highway Construction. Master's Thesis, Hunan University, Changsha, China, 2003.

18. Wu, Y.D.; Liu, J. Research on foamed cement banking for non-uniform differential settlement in used super highway. In Proceedings of the International Conference on Electric Technology and Civil Engineering, Lushan, China, 22-24 April 2011; IEEE: Washington, DC, USA, 2011; pp. 5334-5337.

19. Chen, Y.H.; Shi, G.C.; Cao, D.H.; Ying, H.J.; Wang, X.Q. Control of post-construction settlement by replacing subgrade with foamed cement banking. Chin. J. Geotech. Eng. 2011, 33, 1854-1862.

20. Cao, D.H.; Chen, Y.H.; Wang, X.Q.; Sun, H.; Wei, J. A study on dynamic controlling to embankment settlement of Shen-jia-hu-hang expressway. Highway 2010, 55, 45-48.

21. Nanjing Hydraulic Research Institute. Standard for Geotechnical Testing Method; China Planning Press: Beijing, China, 2019; pp. 16-125. 